\title{
Total Body Clearance for Dose Interval Normalized by Dose
}

National Cancer Institute

\section{Source}

National Cancer Institute. Total Body Clearance for Dose Interval Normalized by Dose. NCI Thesaurus. Code C114230.

The total body clearance for intravascular administration for dose interval divided by the dose. 